\title{
Software production line base on framework1
}

\author{
Yin Shengbin \\ Hebei University, Baoding,071000, China \\ e-mail:ysb@hbu.cn
}

\begin{abstract}
The social need for software continues to improve, but many software companies most be of repeating similar work, it is adverse for the development of the software industry.This paper discusses software product line combining with the framework .The purpose is to make the software can also like the factory assembly line, and make the overall structure of the software rapidly, then it can fine - tune the software that end-users need it to meet their needs.

Keywords: Application Framework; Software Engineering; Component; Software production line
\end{abstract}

\section{Introduction}

Component-Based software development [1] is an important trend in software engineering. Its main promises are reusability and exchangeability of components in a system. Both are achieved through a principle of locality: Every component needs to explicifiy specify what services it provides and what it needs in order to provide these services. The global behaviour of a component-based software system is derived from the local specifications of its components and the network of interconnected components.

Component-Based System technology supports rapid development of complex heterogeneous evolving systems by enhancing reuse and adaptability. The System can be extended and adapted by modifying one or more components.The same component can be used in several systems, and the same system can be deployed in many configurations that differ for some components.

\section{The application framework}

The framework may be considered a part or the whole system reusable design,and is the interaction method of a group of abstract components and component instance. It can be said that a framework is a reusable design component, it builds the system architectures and describes the dependency relationship of the whole design and the Cooperative components, besides responsibility assignment and control process.

${ }^{1}$ This research funded by the project of Baoding science and technology, its number is 12ZG007 
There are two definitions of the application framework now: (1)" framework is the reuse design of all or part of a system, usually make up of a set of abstract classes and cooperation of these classes"[2]. (2) "The framework is a system framework that can be made instantiation by developers" [3]. These two definitions describe the application framework in both sides, the former describes the framework from the angle of the design, putting forward the framework composing and the design mode; the latter describes the purpose of design.

From these two definitions we know:(1) The framework compartmentalizes the classes of application domain according to the system function, and defines main duties of every part of the system, and defines the synergic relation of objects and classes, moreover, limits the control flow too;(2) The framework includes the decision-making of main functional design of its application domain, it defines description and calling rule of the component[4]. So, the framework can be deemed to be an assembled component that can complete main function of system and be extensible. From this meaning, we can define the application framework as: It is a reusable system application model that can assemble necessary function of system and allow dynamic extension, and can be instantiation[8]. For better reuse the framework, the paper divides the framework into two kinds: The function framework and the structure framework. The function framework is a reuse model that can realize an indivisibility function. The structure framework is reuse model that can assemble a set of independent functions into a whole[5].

\section{The framework description}

Because the framework stipulates the architecture of application Domain, the main structure of most applications in the field is the same. Like component library, We can construct domain framework library. The framework mainly contains the following aspects:

Main Framework= interface, property, functions register, function entity Call, Hot Spots\}

Among them:

Functions $=\{$ Items, Relations $\}$

Functions are made up of a set of function items of embedding in the framework and the Relations with entities that realize these functions.

Main Framework framework_name

\{

Interfaces:

Interface element ();

Interface of calling components();

Interface of calling subframework();

Custom design Interface();

Properties:

Initialization (); 
Get properties ();

Set properties ();

Functions search:

Search Subframework Library;

Search Component Library;

Functions register:

Item1:

Load sub_framework Entity 1

Load component Entity 1

ItemN:

Load sub_framework Entity N

Load component Entity N

Function entity Call:

Item1:

Initialization ()

Execute ()

Hot Spots:

Other entities Interface ()

Entities self-adaption control process ();

$\operatorname{Hook}()$;

\}

Sub_Framework $=\{$ Mutual Base Establishment, Frozen Function, Frozen Function Entity Call, Hot Spots

Sub_Framework framework_name

\{

Mutual Base Establishment: \{Controls (); Relative (); Display ()\}

Frozen Functions

Frozen Function Entity Call

\}

Hot Spots

\section{The Domain library}

In Software production line ,the Domain library is made of interface elements, user authentication component, main frame, sub frame, business component and function component, and so on. There are two parts to be described at below: the domain interface elements library(Table1) and the domain frame library(Table2). 
TABLE1 :DOMAIN INTERFACE ELEMENTS LIBRARY

\begin{tabular}{|c|c|c|c|c|}
\hline Element Name & Illustration & Input & Output & Data \\
\hline User login & $\begin{array}{c}\text { Limited access } \\
\text { login }\end{array}$ & $\begin{array}{c}\text { user name and } \\
\text { password }\end{array}$ & $\begin{array}{c}\text { State:IsOk } \\
\text { authority: }\end{array}$ & Client \\
\hline $\begin{array}{c}\text { Customer } \\
\text { information }\end{array}$ & $\begin{array}{c}\text { Information } \\
\text { maintenance }\end{array}$ & $\begin{array}{c}\text { Customer } \\
\text { related } \\
\text { information }\end{array}$ & SQL & \\
\hline \multicolumn{7}{|c|}{} & $\ldots .$.
\end{tabular}

TABLE2:DOMAIN FRAMEWORK LIBRARY

\begin{tabular}{|c|c|c|c|c|c|}
\hline Framework Name & Illustration & Interface & Properties & $\begin{array}{c}\text { Hot } \\
\text { Spots }\end{array}$ & Rule \\
\hline $\begin{array}{c}\text { Sale Main } \\
\text { Framework1 }\end{array}$ & sales market... & $\begin{array}{c}\text { GUI ctrol } \\
\text { Custom } \\
\text { design }\end{array}$ & $\ldots$ & $\ldots$ & $\ldots$ \\
\hline $\begin{array}{c}\text { Order form } \\
\text { Sub_Framework1 }\end{array}$ & $\begin{array}{c}\text { Order form: ...... } \\
\text { Business process: }\end{array}$ & $\ldots$ & $\ldots$ & $\ldots$ & $\ldots$ \\
\hline
\end{tabular}

\section{Software production process}

The ability to adapt software architectures during use time is nowadays a crucial requirement, not only to react on exceptional cases, but also to be able to deploy software for working contexts that cannot be anticipated during design time. In this regard, it must be faced that software adaptation is mostly tackled by end-users of less experienced.

On the production line, the programmer choose some available parts from these corresponding library, according to user Business process, such as: interface elements, user authentication component, main frame, sub frame, business component and function component etc.. Then the programmer provides end_user with the software and instructions, and improves it according to end_user's feedback after using. Final it can be formed of the complete application software. such as Fig.1. 


\section{Conclusion}

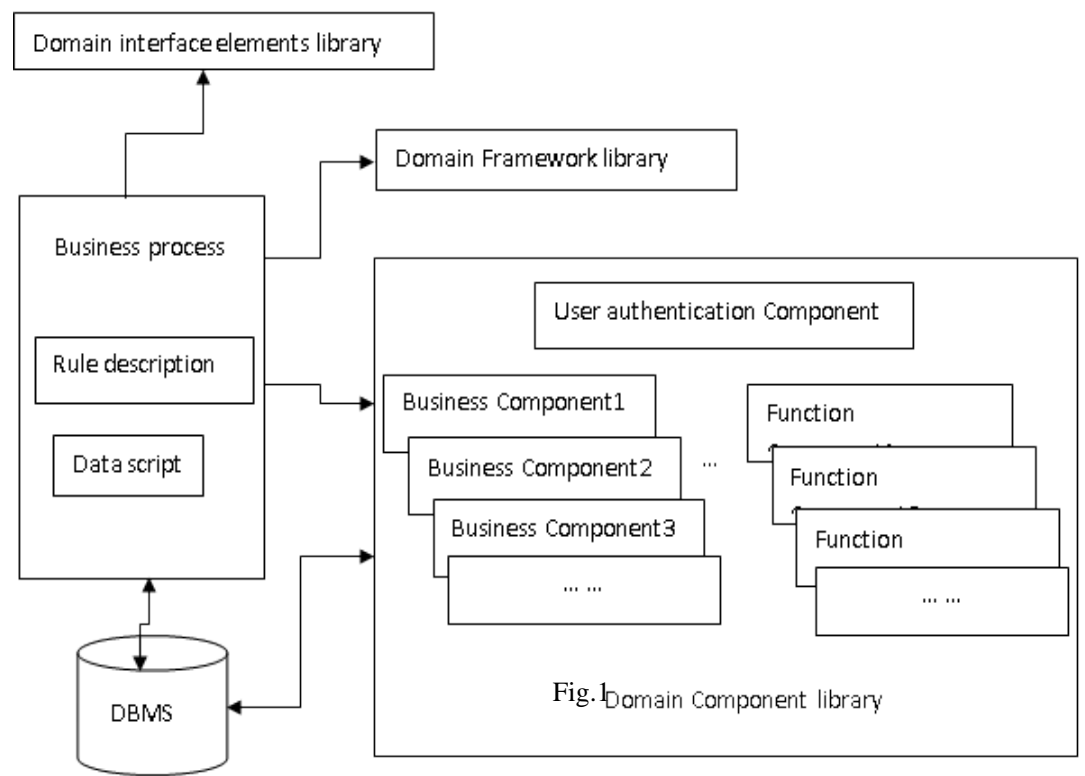

The big granularity reuse of the framework make lower of system development and maintenance cost, make more quickly of developing velocity and reduce the developing persons. To divide framework into layers not only increases the framework reuse degree, but also strengthened with its adaptability, flexibility and extensibility. The design of the application framework oneself is a process that is circulation and iteration. It gets update and increase in the process that continuously applies with practice. We continuously improve the method of compartmentalizing layer of the framework too. In the future we need to farther study dynamic extension of the sub_framework.

\section{References}

[1]. S. H. Edwards. A framework for practical, automated blackbox testing of component-based software. Journal of Software Testing, Verification and Reliability, 11 (2), 2001.

[2]. BJOINER D. Software engineering 3 domains requirements and software design M. Berlin Springer 2006.

[3]. Yang FQ, Mei H, Li KQ. Software reuse and software component technology [J]. Acta Electronica Sinca, 1999,27(2):68 75. 
[4]. G.Succi,R.Wong,E.Liu,M.Smith,Supporting Dynamic Composition of Componens, ICAC04,IEEE,2004:85-86..

[5]. ShengBin Yin, XiaoFan Bian. Construct the Component of the immature realm Using Data Mining[C].Proceedings of 2004 International Conference on Machine Learning and Cybernetics,ShangHai, 2004: 1509 1514. 